\title{
Possibilities of using natural aluminosilicates in the development of medicines at hepatosis in poultry
}

\author{
Marina Semenenko ${ }^{1, *}$, Elena Kuzminova ${ }^{1}$, Vladimir Grin $^{1}$, Evgenia Rogaleva ${ }^{1}$, and Ksenia \\ Semenenko ${ }^{1}$ \\ ${ }^{1}$ Krasnodar Research Center for Animal Husbandry and Veterinary Medicine, 4, Pervomaiskaya str., \\ Krasnodar, 350055, Russia
}

\begin{abstract}
The article discusses the possibility of using natural aluminosilicates as active components of complex medicines at hepatosis in poultry. The use of bentonite from the Kantemirovsky deposit of the Voronezh region in the feed ration of broiler chickens at a dose of $2 \%$ helps to improve the general condition of the poultry, the intensity of their growth and productive indicators. In biochemical homeostasis, activation of metabolic processes such as protein, lipid, carbohydrate and mineral is noted. The inclusion of bentonite in the feeding schedule prevents the development of metabolic changes in hepatocytes and their cytolysis, which is confirmed by a decrease in the level of transaminases - AST by $22.9 \%$, ALT by $69.8 \%$, as well as by the accumulation of endogenous toxic substances in the body. The experiment showed that natural bentonites not only provide correction of metabolic homeostasis, but also contribute to the weakening of endotoxemia in the poultry body, showing hepatoprotective and antitoxic effects.
\end{abstract}

\section{Introduction}

Poultry farming is one of the most efficient, highly profitable and promising sectors of agriculture, because unlike other sectors it does not have seasonality and takes the leading place in satisfying the population with food products throughout the year [1]. The main task of the poultry farming is to raise highly productive poultry with good meat quality of young bird at low feed costs, with the particular attention paid to improving the economic effect of the use of new technologies and their introduction into production.

However, in connection with the improvement of technological processes and the intensification of production in the poultry industry, the risk of a mismatch between the physiological capabilities of the poultry organism and the existing conditions for the feeding increases [2]. To achieve the stable production indicators in poultry, an intensive high-concentrate type of feeding with the rapid growth of bone and muscle mass is used. In this case, the protein synthesis is intensified in the body, the liver experiences tremendous loads, and in case of violation of feeding conditions (poor-quality feed, lack of minerals,

*Corresponding author: sever291@mail.ru 
unsystematic use of antibiotics and other chemotherapeutic agents, the presence of mycotoxins, xenobiotics and other toxicants in the feed), the processes of regeneration and function of hepatocytes are disrupted, which leads to degenerative changes in the body, metabolic disorders and decrease in barrier function [3]. This, in turn, is the trigger for the occurrence of many diseases, and, first of all, liver pathologies, with which most of the metabolic processes of the body are directly or indirectly associated $[4,5,6]$.

On this background, it is necessary to conduct pathogenetic therapy, aimed not only at reducing the intake of toxicants in the body, but also at adequate pharmacological correction with the help of medicines that improve metabolic processes in the liver of poultry, increase its resistance to pathogenic effects, and also contribute to the restoration of its functions with various injuries [7.8].

Recently, in veterinary medicine the interest in natural layered aluminosilicates from the montmorillonite group, which has high sorption properties and versatile pharmacological activity, has significantly increased $[9,10,11]$. Moreover, the biological effect of aluminosilicates can be significantly enhanced by creating therapeutic and prophylactic means on their basis for the treatment of various pathological conditions and metabolic disorders of animals and poultry. The structure of the crystal lattice of aluminosilicates allows loading, transportation and effective release of the pharmacological compounds contained in them, as a result of which it is possible to obtain environmentally friendly medicines with improved antitoxic, hepatoprotective, ion-exchange and antioxidant properties, while preserving the biocompatibility and bioavailability of the components included in them $[12,13]$.

However, to create complex preparations that have the pathogenetic effect, it is necessary to select and pharmacologically evaluate the components that make up these medicines.

In connection with the foregoing, at the preliminary stage of research we conducted an experiment to study the effect of natural aluminosilicates on the metabolic functions of poultry liver.

\section{Materials and Methods}

The experiment was performed on broiler chickens during the fattening period (from 22 to 36 days of rearing), divided into two groups - experimental and control $(\mathrm{n}=50)$. Aluminosilicates (bentonite of the Kantemirovsky deposit) were introduced into the feed rations of chickens of the experimental group at a dose of $2 \%$ of the diet. The poultry of the control group got only the complete feed.

Alkaline-earth bentonite of the Kantemirovsky deposit (Voronezh region, Russian Federation) is a mixture of natural aluminosilicates, the leading place among which belongs to montmorillonite $\left(\mathrm{Al}_{2} \mathrm{O}_{3} \cdot 4 \mathrm{SiO}_{2} \cdot \mathrm{n} \cdot \mathrm{H}_{2} \mathrm{O}\right)$ - from 60 to $\left.73 \%\right)$, the rest belongs to clay minerals of the other types in the form of grains, aggregates and fragments: carbonates, oxides and hydroxides of iron, manganese and aluminum, as well as minerals - quartz, opal, feldspars, mica, etc. The generalized crystal chemical formula of dioctahedral montmorillonite is the following: $(\mathrm{Ca}, \mathrm{Mg}, .).\left(\mathrm{Al}, \mathrm{Fe}^{3+}, \mathrm{Mg}, . ..\right) 2(\mathrm{OH})_{2}\left[(\mathrm{Si}, \mathrm{Al})_{4} \mathrm{O}_{10}\right] \mathrm{nH}_{2} \mathrm{O}$.

The chemical and microelement composition of bentonite clays of the Kantemirovsky deposit are presented in Table 1. 
Table 1. Chemical and microelement composition of bentonite clays of the Kantemirovsky deposit.

\begin{tabular}{|c|c|c|c|}
\hline $\begin{array}{c}\text { Chemical } \\
\text { composition, } \\
\text { mass \% }\end{array}$ & $\begin{array}{c}\text { Fluctuation limits } \\
\text { depending on the } \\
\text { deposit }\end{array}$ & $\begin{array}{c}\text { Content of } \\
\text { microelements, } \\
\text { mg / kg }\end{array}$ & $\begin{array}{c}\text { Fluctuation limits } \\
\text { depending on the } \\
\text { deposit }\end{array}$ \\
\hline $\mathrm{SiO}_{2}$ & $64.67-68.52$ & $\mathrm{Cu}$ & $13.0-16.8$ \\
\hline $\mathrm{Al}_{2} \mathrm{O}_{3}$ & $13.23-14.81$ & $\mathrm{Si}$ & $24.6-37.2$ \\
\hline $\mathrm{Fe}_{2} \mathrm{O}_{3}$ & $4.34-5.51$ & $\mathrm{Mg}$ & $40.0-56.6$ \\
\hline $\mathrm{CaO}$ & $0.65-0.98$ & $\mathrm{Zn}$ & $29.0-49.4$ \\
\hline $\mathrm{MgO}$ & $1.31-1.42$ & $\mathrm{Co}$ & $4.0-4.5$ \\
\hline $\mathrm{K}_{2} \mathrm{O}$ & $2.23-2.39$ & $\mathrm{~J}$ & $0.08-0.15$ \\
\hline $\mathrm{Na}_{2} \mathrm{O}$ & $0.3-0.75$ & $\mathrm{Mo}$ & $0.8-1.3$ \\
\hline Titanium oxide & $0.91-0.93$ & $\mathrm{Cr}$ & $62.9-108.7$ \\
\hline Phosphorus oxide & $0.06-0.07$ & $\mathrm{Cd}$ & $0.15-0.16$ \\
\hline Sulfur oxide & $0.07-0.15$ & $\mathrm{Ba}$ & $1.0-3.0$ \\
\hline
\end{tabular}

At the same time, a distinctive feature of clays of the Kantemirovsky deposit in addition to the presence of a complex of essential macro- and microelements is their high content of amorphous silicon (cristobalite) - from 24.6 to $37.2 \mathrm{mg} / \mathrm{kg}$. Amorphous silicon, in contrast to crystalline, is physiologically active and better absorbed by the body.

During the entire experimental period, the chickens were physically controlled, and the severity of the syndrome complex of metabolic disorders of the liver in terms of poultry safety, biochemical blood counts, body weight dynamics, and pathomorphological changes in the liver were taken into account.

Biochemical studies of blood serum were performed on an automatic analyzer - Vitalab Selectra Junior with the software version 1.0. (open system for photometric tests, manufactured by Vital Scientific N. V. Netherlands) using reagents from ELITech Clinical Systems (France) and Analyticon biotechnologies AG (Germany).

The level of endogenous intoxication (medium mass molecules - MMM) was determined by the method of N.I. Gabrielyan and V.I. Lipatova (1984) at various wavelengths of the spectrophotometer.

The statistical processing of the results was carried out using the statistical software packages ARCADA, Microsoft Excel XP and Statistical for Windows. The study of quantitative signs was evaluated by comparing the mean values of two sample sets with the determination of Student's criterion and significance level (p).

\section{Results}

During the experiment, a positive influence of bentonite on the clinical status and body weight of experimental broiler chickens was determined (Table 2).

Table 2. The growth rate of broiler chickens when using bentonites in the diets $(M \pm m ; n=50)$.

\begin{tabular}{|l|c|c|c|}
\hline \multicolumn{1}{|c|}{ Groups } & $\begin{array}{c}\text { Body weight at the } \\
\text { beginning of the } \\
\text { experiment, } \mathbf{g}\end{array}$ & $\begin{array}{c}\text { Body weight at the } \\
\text { end of the } \\
\text { experiment, } \mathbf{g}\end{array}$ & $\begin{array}{c}\text { The average daily } \\
\text { gain, } \mathbf{g}\end{array}$ \\
\hline $\begin{array}{l}\text { 1 experimental (main diet }+2 \% \\
\text { of bentonite) }\end{array}$ & $1048.4 \pm 10.2$ & $2235.6 \pm 12.4$ & $84.8 \pm 5.2 *$ \\
\hline 2 control (main diet) & $1051.3 \pm 8.9$ & $2147.1 \pm 10.8$ & $78.3 \pm 3.6$ \\
\hline
\end{tabular}

Where significance level: $* \mathrm{p} \leq 0.05$

The use of bentonite has improved the general condition of the poultry, the growth rate and productive indicators. In the experimental group, the average daily gain in body weight of chickens exceeded the values of the control analogues by $8.3 \%$. The positive effect of 
aluminosilicates in the digestive tract is caused by the fact that, firstly, they slow down the rate of food passage through the gastrointestinal tract by stabilizing organic compounds, and secondly, they stimulate intestinal microvilli, increasing digestibility, biological value and feed conversion.

Optimization of physiological parameters of experimental chickens was confirmed by the positive changes in blood homeostasis (Table 3).

The introduction of bentonite into the feed stimulated the protein-synthetic function of the liver, which was manifested by higher values of the total protein, the level of which in the experimental group increased by $10.4 \%$ relative to the background values and by $14.0 \%$ compared to the control broiler chickens.

Its use has influenced the state of carbohydrate and lipid metabolism. Thus, the glucose concentration during the experiment in an experimental poultry increased by $6.1 \%$, triglycerides increased by $18.9 \%$, cholesterol increased by $13.6 \%$. Compared to control analogues, the differences in these indicators were more significant $-10.0 \%, 62.9 \%$ and $19.7 \%$, respectively. A similar effect was because of the physicochemical characteristics of natural aluminosilicates, which provide metabolic activity due to the wide range of microelements that make up its composition. Water-soluble, readily exchanged metal cations are included in redox reactions as coenzymes that determine the subsequent regulation and activation of the biochemical processes in the body.

Table 3. Influence of bentonite on the biochemical blood parameters of broiler chickens $(\mathrm{M} \pm \mathrm{m}$; $\mathrm{n}=10)$.

\begin{tabular}{|l|c|c|c|}
\hline \multirow{2}{*}{\multicolumn{1}{|c|}{ Indicators }} & Background & \multicolumn{2}{c|}{ Groups } \\
\cline { 3 - 4 } & indicators & experimental & control \\
\hline Total protein, g / 1 & $37.6 \pm 1.2$ & $41.5 \pm 0.84$ & $36.4 \pm 0.82$ \\
\hline Glucose, mmol / 1 & $11.4 \pm 0.44$ & $12.1 \pm 0.38$ & $11.0 \pm 0.48$ \\
\hline Triglycerides, mmol / & $0.74 \pm 0.03$ & $0.88 \pm 0.01 * *$ & $0.54 \pm 0.02$ \\
\hline Cholesterol, mmol / 1 & $4.12 \pm 0.19$ & $4.68 \pm 0.12^{* * *}$ & $3.91 \pm 0.13$ \\
\hline Calcium, mmol / & $2.46 \pm 0.05$ & $2.82 \pm 0.18^{* * *}$ & $2.51 \pm 0.14$ \\
\hline Phosphorus, mmol / 1 & $2.24 \pm 0.09$ & $2.22 \pm 0.10$ & $2.44 \pm 0.13$ \\
\hline Zinc, mcg\% & $186.2 \pm 7.24$ & $211.4 \pm 6.71^{* *}$ & $179.3 \pm 9.14$ \\
\hline Copper, mcg\% & $52.3 \pm 4.2$ & $61.5 \pm 3.7$ & $51.7 \pm 2.1$ \\
\hline Iron, mcg\% & $19.4 \pm 2.5$ & $23.7 \pm 1.48^{*}$ & $20.6 \pm 3.4$ \\
\hline AST, Units & $261.6 \pm 10.3$ & $263.8 \pm 5.2$ & $321.4 \pm 12.7$ \\
\hline ALT, Units & $18.2 \pm 0.9$ & $14.6 \pm 0.4 * *$ & $24.8 \pm 0.7$ \\
\hline $\mathrm{MMM}_{254}, \mathrm{AU}$ & $0.18 \pm 0.03$ & $0.16 \pm 0.01 * *$ & $0.25 \pm 0.2$ \\
\hline $\mathrm{MMM}_{280}, \mathrm{AU}$ & $0.27 \pm 0.01$ & $0.23 \pm 0.01 *$ & $0.33 \pm 0.01$ \\
\hline
\end{tabular}

Where significance level: * $-\mathrm{p} \leq 0.001 ; * *-\mathrm{p} \leq 0.01 ; * * *-\mathrm{p} \leq 0.05$

Bentonite contributed to the correction of mineral metabolism, providing a more complete assimilation of calcium by the poultry, an increase in the dynamics of which amounted to $25.9 \%$ in comparison with the background indicators and to $12.4 \%$ in comparison with the control group of chickens.

If we talk about other mineral components of bentonite clays, which are included in the mineral exchange of broiler chickens, the differences in the contents of zinc, copper and iron between the groups also had certain differences. By the end of the study, zinc in the blood of experimental chickens increased by $13.5 \%$, copper increased by $17.6 \%$, iron increased by $22.2 \%$, respectively. In analogues of the control group, copper and iron indicators remained at the level of background studies, while zinc concentration decreased by $3.7 \%$. Namely, the minerals that make up bentonite have proved to be donors of macroand micronutrients. 
It should be noted that in the pathogenesis of the development of metabolic disorders in animals and poultry, the main role is given to damage of the cell membranes and organelles of hepatocytes, and first of all, mitochondria, which entails a dysfunction of the liver cells themselves, leading, in the future, to the development of the general metabolic pathology.

In this case, the inclusion of bentonite in the feeding schedule prevented the development of metabolic changes in hepatocytes and their cytolysis. This is confirmed by the absence of changes in the activity of liver aminotransferases in the experimental poultry, in which the values of aspartate aminotransferase remained at the background level by the end of the studies, whereas in control chickens it increased by $22.9 \%$. The level of aspartate aminotransferase between groups revealed differences that are more significant. The ALT level in the control group of chickens increased by $36.3 \%$ compared to the initial indicators, and it increased by $69.8 \%$ in relation to the experimental chickens. Moreover, since alanine aminotransferase belongs to the cytoplasmic enzymes, its significant increase in blood serum indicates a violation of the hepatocyte cell membrane and a weakening of the barrier function of the poultry liver.

One of the factors affecting the functional activity of liver cells is a violation of homeostasis, resulting from the accumulation of endogenous toxic substances in the body that have pronounced biological activity and lead to the development of endotoxemia [14]. As the main "toxicity marker" of biological media act the so-called medium mass molecules (MMM) - the endogenous peptides with a molecular weight of 500-2000 daltons (D), which are formed during proteolysis in damaged tissues, as well as in the plasma itself when the proteolytic enzymes enter the bloodstream, and capable to accumulate in the body, exerting toxic effects on it [15]. Violations of metabolic processes in animals and poultry often lead to the occurrence of the pathological conditions of various origins in liver, with the subsequent development of metabolic intoxication syndrome. Therefore, the study of the level of medium mass molecules in biological media can significantly expand the possibilities of a deep understanding of the processes occurring in the body, and is one of the most informative ways to assess the severity of endotoxemia. In addition, since the sizes of the molecules of medium mass vary significantly, their measurements are carried out at different wavelengths.

During the study it was found out that by the end of the experiment in indicators of the level of MMM of the experimental group of broilers there was a decrease by $11.1 \%$ (at a wavelength of $\lambda=254 \mathrm{~nm}$ ) and a decrease by $14.8 \%$ (at a wavelength of $\lambda=280 \mathrm{~nm}$ ). Whereas in the group of analog chickens, the concentration of medium molecular peptides, on the contrary, increased by $38.9 \%$ and by $22.2 \%$ relative to the initial indicators. Moreover, the differences between the groups were more significant, accounting for $56.3 \%$ and $43.8 \%$, respectively.

Thus, the spectrum of biological activity of bentonites causes a decrease in the level of medium molecules and, first of all, peptides with a lower molecular weight, contributing to the decrease in the severity of endogenous toxicosis because of the high sorption properties.

At the end of the experiment, broiler chickens from each group $(n=5)$ were removed from the experiment by decapitation under ether anesthesia for pathological and anatomical examination of the liver.

It was found out that the most pronounced structural and histological changes in liver were determined in control chickens, characterized by heterogeneity of color and claybrown areas.

Histological examination of the organ revealed a violation of the beam structure, pronounced granularity of hepatocytes, blood supply of venous vessels, circulatory proliferation of lymphocytes, various forms of nuclei of epithelial cells, and the presence of fatty vacuoles. 
The examination of the liver of the experimental group poultry revealed changes due to some increase in its size. In the central and peripheral parts of the liver, hepatocytes were slightly increased in size with weakly expressed granularity.

\section{Conclusion}

The conducted studies have shown that natural bentonites have a pronounced effect on the metabolic functions of liver, contribute to the normalization of the biochemical picture of blood and improve the clinical status of poultry.

The use of natural aluminosilicates, characterized by the presence of direct and indirect biological effects, provides the correction of metabolic homeostasis of animals in the framework of physiological constants. Moreover, the creation on their basis of the complex medicines with the directed effect on liver cells will allow having a pronounced pharmacotherapeutic effect in hepatopathies of animals and poultry.

\section{References}

1. E.V. Vasiliev, E.V. Shalavin, Technologies and technical means of mechanized production of crop and livestock products 92, 173-185 (2017)

2. I.A. Egorov, Poultry farming 4, 11-16 (2014)

3. M.P. Semenenko, E.V. Kuzminova, M.N. Sokolov, Yu.V. Kozlov, Veterinary medicine of Kuban 2, 4-6 (2015)

4. L.I. Drozdova, U.I. Kundyukova, Agrarian Bulletin of the Urals 5(71), 68-70 (2010)

5. S.E. Lehman, S.C. Larsen, Environ. Sci.: Nano 1, 200-213 (2014) https://doi.org/10.1039/C4EN00031E.

6. P.P. Shchetinin, M. Shurupova, Key Engineering Materials 683, 358-362 (2016) https://doi.org/10.4028/www.scientific.net/kem.683.358

7. V.A. Myshkin, D.A. Enikeev, D.V. Srubilin, A.R. Gimadieva, Scientific Review 3, 8898 (2016)

8. M.P. Semenenko, N.N. Zabachta, M.N. Sokolov, E.V. Kuzminova, Journal of Pharmaceutical Sciences and Research (JPSR) 10(1), 146-147 (2018)

9. Ali Gilani, Hassan Kermanshahi, Abolghasem Golian, Saeed Seifi, Turk. J. Vet. Anim. Sci. 40, 255-262 (2016) doi:10.3906/vet-1501-103.

10. A.M. Ezhkova, A.Kh. Yapparov, T.Yu. Motina, I.A. Yapparov, V.O. Ezhkov, Scientific notes KSAVM named after N.E. Bauman 4, 285-289 (2012)

11. M. Safaei, F. Boldaji, B. Dastar, S. Hassani, M.S.A. Mutalib, R. Rezaei, Asian J. Anim. Vet. Adv. 9, 56-63 (2014) https://doi.org/10.3923/ajava.2014.56.63

12. E.V. Tyapkina, M.P. Semenenko, E.V. Kuzminova, Veterinary pathology 2(52), 73-81 (2015)

13. E.T. Zhilyakova, A.B. Bondarev, Remedium 10, 40-47 (2014)

14. A.A. Gidulyanov, Ecosystems, their optimization and protection 10, 186-188 (2014)

15. M.P. Semenenko, E.V. Kuzminova, E.V. Tyapkina, A.A. Abramov, K.A. Semenenko, Journal of Pharmaceutical Sciences and Research (JPSR) 9(9), 1573-1575 (2017) 